\title{
Asthma and dental erosion
}

\section{Manuel ST ${ }^{1}$, Kundabaka $\mathbf{M}^{2}$, Shetty $\mathbf{N}^{3}$, Parolia $\mathbf{A}^{1}$}

${ }^{1}$ Assisstant professor, ${ }^{2}$ Professor, ${ }^{3}$ Associate professor, Department of Conservative Dentistry and Endodontotics, Manipal College of Dental Science, Mangalore, India

\begin{abstract}
Asthma is a chronic inflammatory condition of the airway, characterised by the presence of airflow obstruction which is variable over short periods of time, or is reversible with treatment. Medication comprises of bronchodilators, corticosteroids and anticholinergic drugs. Most asthma drugs are inhaled using various forms of inhalers or nebulizers. Inhaled drugs must be used regularly. The effects of these drugs on the dentition such as tooth decay and erosion have been a subject of debate among dental practitioners. Asthmatic medications can place the patient at risk of dental erosion by reducing salivary protection against extrinsic or intrinsic acids. Asthmatic individuals are one of the higher risk groups suffering from dental erosion. Therefore patients with bronchial asthma should receive special prophylactic attention. This article presents a case of an asthmatic with dental manifestations and reviews the possible causes and management of the same.
\end{abstract}

Key words: Asthma, dry powder inhalers, beta-2 agonist, gastro-esophageal reflux, dental erosion.

$\mathrm{T}^{\mathrm{s}}$ he prevalence of asthma has increased steadily over the latter part of the last century. Currently estimates suggest that 300 million people world-wide suffers from asthma and an additional 100 million may be diagnosed with asthma by $2025^{1}$. Asthma is a chronic inflammatory condition that causes the airways (bronchi) to produce excess mucus and close, making breathing difficult. It is characterised by the presence of airflow obstruction which is variable over short periods of time, or is reversible with treatment. The aetiology of asthma is complex, and multiple environmental and genetic determinants are implicated.

Treatment has two main objectives: first, to control and reduce inflammation and, second, to reopen the airways. Drugs that achieve the first goal are called anti-inflammatory agents, and those that bring about the second are called bronchodilators. Many asthma sufferers inhale these medications. Medications for asthma fall into two categories: Quick relief medication comprises of short acting bronchodilators, systemic corticosteroids and anticholinergic drugs. Long-term control medication includes anti-inflammatory agents, long-acting bronchodilators, and leukotriene modifiers ${ }^{2}$. Most asthma drugs are inhaled using various forms of inhalers or nebulizers. Inhaled drugs must be used regularly as prescribed and the patient carefully trained in their use in order for them to be effective and safe. Several studies have examined a possible association between erosion and inhaled medication used to treat asthma. The effects of these drugs on the dentition such as tooth decay and erosion have been a subject of debate among dental practitioners.

\section{Review of the literature}

Inhalers which deliver these medicaments may be used up to four times a day over long periods and since more than $5 \%$ of the population is affected by asthma, erosion produced by associated medication could pose a significant population-wide dental health problem. However the evidence for such an association is unclear. Although Shaw et al and McDerra et al reported that children with asthma were at an increased risk of developing erosion ${ }^{3,4,5}$; few other studies yielded no clear association between asthma and dental erosion ${ }^{6}$.

Asthmatic medications can place the patient at risk of dental erosion by reducing salivary protection against extrinsic or intrinsic acids ${ }^{7}$ (Table 1).

\section{Correspondence}

Dr. Manuel S. Thomas

Assist. Prof., Dept of Conservative Dentistry and Endodontotics

Manipal College of Dental Science

Karnataka - 575001, India

E-mail: manuel2dr@yahoo.co.in 
Saliva is considered to be one of the main neutralizing factors in the pathogenesis of dental erosion. The oral clearance of dietary acid will be related to the rate of secretion and buffering capacity of saliva ${ }^{8}$. There is newer evidence that medicines taken by dry-power inhaler may cause tooth erosion in children by changing the mouth's chemical environment. They reduce the production of saliva, affecting the mouth's natural way of maintaining its chemical balance. Ryberg et al found a lowered secretion rate of whole and parotid saliva, decreased secretion of saliva proteins and higher streptococcus mutans counts in asthmatic subjects treated with beta 2-adrenoceptor agonists than in matched healthy controls ${ }^{9}$. The effects of the beta adrenoceptors on salivary composition and flow rate were further investigated by Kargul et $\mathrm{al}^{10}$. They considered the effects of Salbutamol and Fluticasone proprionate inhalers on plaque and saliva $\mathrm{pH}$ in asthmatic children aged 6-14 years. The authors found that $\mathrm{pH}$ values decreased in plaque and saliva in the 30 min following inhalation of the drugs. In asthma, drug-induced xerostomia is dose-dependent. At higher bronchodilator concentrations a reduction is seen in the natural anti-bacterial compounds and buffering agents normally found in saliva such as $\operatorname{IgA}$, calcium, lactoferrin and total protein. Reduced salivary buffering power makes patients more vulnerable to the erosive action of acids, either extrinsic or intrinsic.

Anti-asthmatic drugs can cause tooth erosion in children and the culprit is thought to be the newer dry-powder inhalers. Dry powder inhalers are convenient and easy to use. They dispense medicine directly to the place where it is needed, greatly reducing side effects as compared with medicines taken as pills or tablets. They also deliver medicine to the troubled site quickly, without need for absorption, digestion and circulation. And they can deliver long-lasting anti-inflammatory benefits or short-acting, quick-relief bronchodilation when needed. No other way of taking asthma drugs is so versatile. The powder versions of preventer therapies e.g. Becotide and Flixotide and relief bronchodilators e.g. Ventolin and Bricanyl, the mainstays of asthma treatment, are acidic with a $\mathrm{pH}$ below $5.5^{11,12}$. Reports from clinical experiments demonstrated a fall in the $\mathrm{pH}$ of interdental plaque and saliva during the thirty minutes following the use of inhaler medication for asthma. Enamel starts to dissolve below $\mathrm{pH}$ 5.5. The powder in the puffers can erode the tooth enamel when used regularly ${ }^{13}$. It is also possible that there will be an increased consumption of drinks to compensate for oral dehydration, often drinks with a low $\mathrm{pH}$, which could also cause erosion ${ }^{4}$.

Conditions such as vomiting, heartburn and stomach problems were more commonly reported in the asthma and erosion groups and were associated with dental erosion. Harding reported that gastro-oesophageal reflux symptoms are more prevalent in asthma patients compared with control populations, with a prevalence of approximately $75 \%{ }^{14}$. Part of the inhaled medication might be swallowed. This may cause minor stomach upset or "heartburn," which can do longterm damage. The beta 2 adrenoreceptors and drugs such as Aminophylline and Theophylline can cause relaxation of other smooth muscles such as the lower oesophageal sphincter. This relaxation is associated with gastrooesophageal reflex ${ }^{4}$. The relationship between gastrointestinal disease and dental erosion has been noted by several researchers $15,16,17$. So, this may also provide at least a partial explanation of the relationship between asthma and dental erosion.

\section{Management}

- Proper oral hygiene instructions: Since it has been shown that the dry powder inhalers used for asthma have an acidic $\mathrm{pH}$, to offset these side effects, the patients should be persuaded to get into the habit of rinsing their mouth immediately after using the inhaler with neutral $\mathrm{pH}$ or basic mouth rinses, such as liquid antacids, sodium bicarbonate in water, milk or neutral sodium fluoride mouth rinses. Patients should also be instructed not to brush their teeth immediately after exposure to acids as it may damage the already weakened enamel ${ }^{17}$.

- Modification of drug delivery system: Another simple measure to reduce tooth erosion is by using a spacer device to deliver the powder. Spacers such as 'Volumetric' are clear plastic balloonlike devices with a one-way valve. By providing a spacer between the inhaler and the mouth, the velocity of the powder is reduced, thus reducing the ferocity of the impact of the powder on the oropharnyx. The time lag in delivery permits more of the propellant to evaporate; hence more particles are inhaled into the lung.

- Increasing the salivary flow and buffering capacity: Use of sugarless chewing gum to stimulate salivary flow and buffer the oral acids should also be encouraged ${ }^{18}$. Experimentally, chewing gum for at least one minute after using an inhaler neutralized the interdental plaque $\mathrm{pH}^{10}$. Adult asthmatics can be advised to use saliva substitutes, sip plain water and use daily fluoride mouth rinse to compensate for the xerostomia. All age groups of asthmatics should be made aware of the problem and encouraged to have regular dental check-ups.

- Treatment of gastric reflex: The evidence is strong that gastro-oesophageal reflux plays an important role in some patients with asthma. Presumptive diagnosis by the dentist should lead to appropriate referral for further investigation. Most often it will 
be to a gastroenterologist for gastroscopy and 24hour measurement of oesophageal $\mathrm{pH}$. Anti-acid drugs have to be prescribed to the patients having gastrointestinal disease ${ }^{19}$.

- Definitive treatment: Once the preventive measures have been instituted, definitive restoration of the dentition can begin. Indication for restoration may include protection of the remaining tooth structure, aesthetic consideration, prevention of dentin sensitivity, severe vertical discrepancies and temporomandibular joint dysfunction. Treatment may range from simple to exceedingly complex, depending on the extent of tooth destruction and the ability of the masticatory system as a whole to adapt ${ }^{19}$.

\section{Case report}

A male patient 43 years of age came to the Department of Conservative dentistry and Endodontics, with a chief complain of sensitivity to cold food. He also complained of discoloured restorations in his upper and lower front teeth. Patient's medical history revealed that he is an asthmatic on medication. He has been suffering from this chronic inflammatory condition since 18 years and his asthmatic attacks are triggered by dust. Since then he has regularly been on medication (table 2).

When asked about his oral hygiene habits, it was understood that the patient brushes his teeth 2 to 3 times a day, immediately after the use of the inhaler.

Clinical examination revealed saucer shaped loss of tooth structure on the labial surface of the teeth 23,34 , 35, 44 and 45. There were also discoloured composite restorations on the labial surface of the teeth 22, 31, 32 and 33 (Fig 1). Minimal attrition of posterior teeth was also seen.

Table 1: Possible cause for increased incidence of erosion in asthmatics

I) Reduced buffering capacity and salivary flow rate caused by $\beta 2$ agonist

II) Increased exposure of the teeth to acids

- Extrinsic source - Acidity of medication

- Acidic drinks

- Intrinsic source - Gastro-esophageal reflux

Table 2: Medication taken by the patient.

\begin{tabular}{|l|l|l|l|}
\hline Medication purpose & Drug class & Generic name & Administration \\
\hline $\begin{array}{l}\text { Long term relief medica- } \\
\text { tion ( to prevent asth- } \\
\text { matic attacks and control } \\
\text { chronic symptoms) }\end{array}$ & Inhaled corticosteroids & Budesonide & Inhaler (2 puffs, twice daily) \\
\hline $\begin{array}{l}\text { Quick relief medication } \\
\text { for mild asthmatic attacks }\end{array}$ & $\begin{array}{l}\text { Short acting beta-2 } \\
\text { agonist }\end{array}$ & Salbutamol & Inhaler (2 puffs as required) \\
\hline $\begin{array}{l}\text { To control severe ex- } \\
\text { acerbation of bronchial } \\
\text { asthma }\end{array}$ & $\begin{array}{l}\text { Corticosteroid, Beta-2- } \\
\text { agonist, Anticholinergic. }\end{array}$ & \begin{tabular}{l} 
Budesonibe, Salbutamol, \\
\cline { 2 - 5 }
\end{tabular} & Systemic corticosteroid \\
\hline $\begin{array}{l}\text { To treat gastritis and gas- } \\
\text { tric regurgitation }\end{array}$ & Proton pump inhibitor & Omeprazole & Nebuired) \\
\hline
\end{tabular}




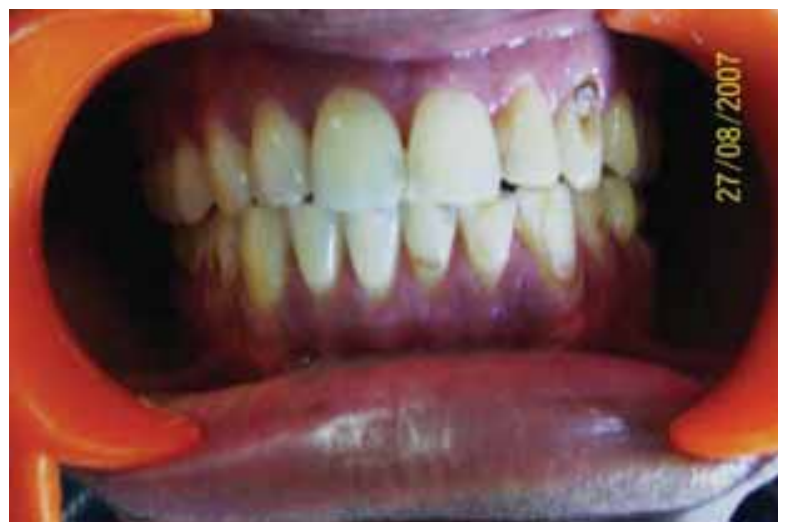

Fig 1: Pre-operative photograph shows saucer shaped loss of tooth structure on the labial surface of the teeth $23,34,35,44$ and 45 and discoloured composite resin restorations on the labial surface of the teeth 22, 31, 32 and 33

\section{Discussion}

The most probable cause for tooth structure loss in this patient could be due to the brushing of the teeth immediately after the use of dry powder inhaler. The reason for tooth wear also could be supplemented by drug induced gastritis for which he is taking medication.

Treatment plan: The patient was instructed to rinse his mouth with a fluoride mouth wash immediately after the use of the inhaler. He was also instructed not to brush his teeth as soon as the inhaler is used. The defects on the labial surfaces of teeth $23,34,35,44$ and 45 where restored with composite resin. The discoloured composite restorations on the labial aspect of the teeth 22, 31, 32 and 33 were also replaced (fig 2).

\section{Conclusion}

Asthmatic individuals are one of the higher risk groups suffering from dental erosion. Therefore patients with bronchial asthma should receive special prophylactic attention for the condition.

\section{References}

1. Boon AN, Colledge RN, Walker RB. Davidson's Principles and Practice of Medicine. In: Sharpe MC, Potts SG, editors. Medical Psychiatry. 20th ed. London, UK: Churchill Livingstone Elsevier; 2006.

2. McPhee SJ, Papadakis MA, Tierney LM. Current medical diagnosis and treatment-2007. 46th ed. US: McGraw-Hill Professional; 2006.

3. Shaw L, AL-Dlaigan YH, Smith A. Childhood asthma and dental erosion. J Dent Child. 2000; 67:102-6.

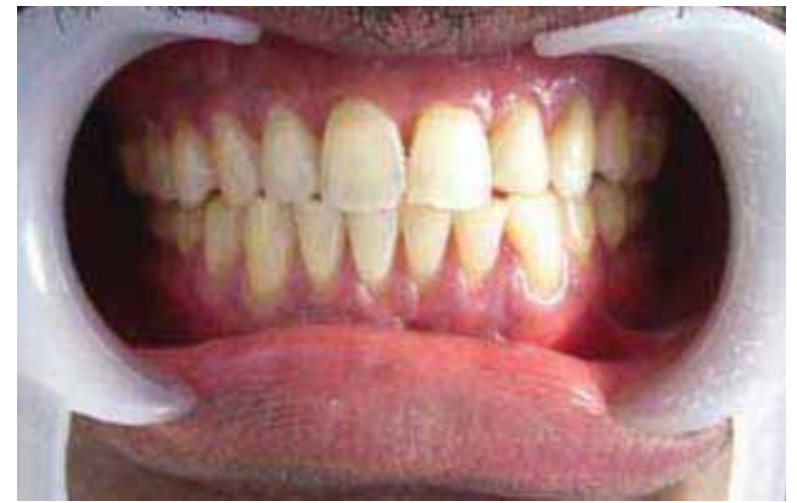

Fig 2: Post-operative photograph shows the restoration of the erosive lesions and the replacement of discoloured restoration with composite resin.

4. Al-Dlaigan YH, Shaw L, Smith AJ. Is there a relationship between asthma and dental erosion? A case control study. Int J Paediatr Dent. 2002; 12:189-200.

5. McDerra JC, Pollard MA, Curzon MEJ. The dental status of asthmatic British school children. Paediatric Dentistr.y 1998; 20: 281-7.

6. Dugmore CR, Rock WP. Asthma and tooth erosion. Is there an association? Int J Paediatr Dent. 2003; 13:417-24.

7. Sivasithamparam K, Young WG, Jirattanasopa V, Priest J, Khan F, Harbrow D, Daley TJ. Dental erosion in asthma: a case-control study from south east Queensland. Aust Dent J. 2002; 47:298-303.

8. Meurman JH, ten Cate JM. Pathogenesis and modifying factors of dental erosion. European Journal of Oral Sciences. 1996; 104: 199-206.

9. Ryberg M, Moller C, Ericson T. Effect of beta-2 adrenoceptor agonists on saliva proteins and dental caries in asthmatic children. Journal of Dental Research. 1987; 66: 1404-6.

10. Kargul B, Tanboga I, Ergeneli S, Karakoc F, Dagli E. Inhaler medicament effects on saliva and plaque $\mathrm{pH}$ in asthmatic children. Journal of Clinical Pediatric. Dentistry 1998; 22: 137-40.

11. O'Sullivan EA, Curzon ME. Drug treatments for asthma may cause erosive tooth damage. $\mathrm{Br}$ Med J. 1998; 317: 820.

12. Randell TL, Donaghue KC, Ambler GR, Cowell CT, Fitzgerald DA, VanAsperen P. Safety of the newer inhaled corticosteroids in childhood asthma. Paediatr Drugs. 2003; 5: 481-504. 
13. Tootla R, Toumba KJ, Duggal MS. An evaluation of the acidogenic potential of asthma inhalers. Archives of Oral Biology, 2004; 49: 275-83.

14. Harding SM. Gastroesophageal reflux and asthma: Insight into the association. Journal of Allergy and Clinical Immunology. 1999; 104: 251-9.

15. Sontage SJ. Gastroesophageal reflux and asthma. American Journal of Medicine. 1997; 103: 84S-90S.

16. Bartlett DW, Evans DF, Smith BGN. The relationship between gastro-oesophageal reflux disease and dental erosion. Journal of Oral Rehabilitation. 1996; 23: 289-297.
17. Lazarchik DA, Filler SJ. Effects of gastroesophageal reflux on the oral cavity. American Journal of Medicine. 1997; 103: 107S-113S.

18. Imfeld $\mathrm{T}$. Prevention of progression of dental erosion by professional and individual prophylactic measures; Eur J Oral Sci. 1996; 104: 215-20.

19. Holbrook WP, Arnadottir IB, Kay EJ. Prevention. Part 3: Prevention of tooth wear. $\mathrm{Br}$ Dent J. 2003; 195: 75-81. 